\title{
perifèria
}

Número 18, junio 2013

http://revistes.uab.cat/periferia

\section{Museo de los Desplazados}

Left Hand Rotation

www.lefthandrotation.com

www.museodelosdesplazados.com

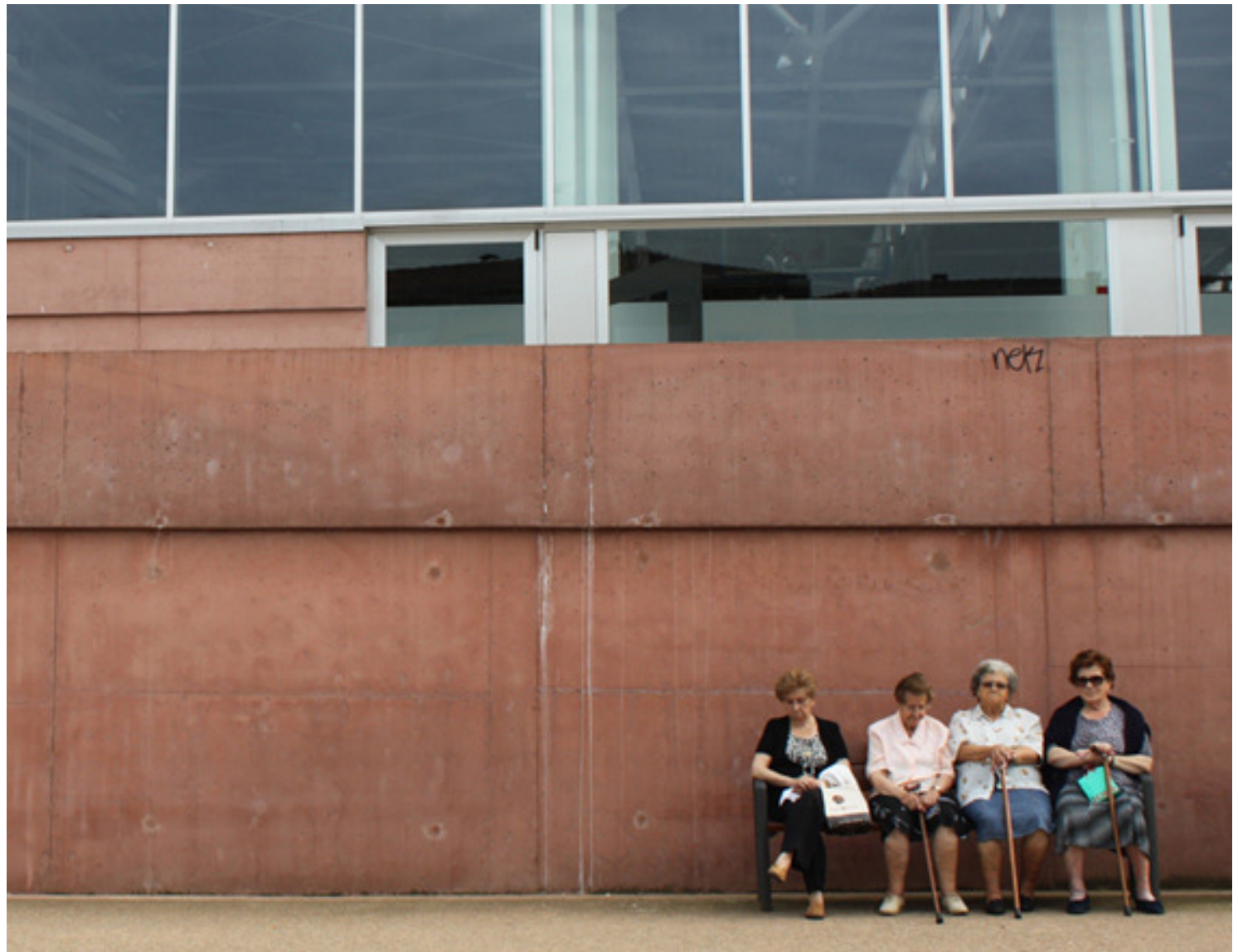

\section{Resumen}

Museo de los Desplazados es una plataforma de colaboración que surge como conclusión del proyecto "Gentrificación no es un nombre de señora", en el que se analiza el papel de la cultura en los procesos de gentrificación.

Palabras clave: Gentrificación, cultura, archivo, memoria, identidad, prácticas colaborativas. 


\title{
perifèria \\ Número 18, junio 2013 \\ http://revistes.uab.cat/periferia
}

\begin{abstract}
Museo de los Desplazados is a collaboration platform that comes as a conclusion of the project "Gentrificación no es un nombre de señora", in which we examines the role of culture in the process of gentrification.
\end{abstract}

Keywords: Gentrification, culture, archive, memory, identity, collaborative practices.

\section{Morir de éxito}

Altos niveles de capital simbólico acumulados en una misma área favorecen la llegada de inversión privada y la demanda de residencia por parte de las clases acomodadas a la zona, con el consiguiente aumento del riesgo de gentrificación. La instrumentalización que de la cultura se hace, a favor de estos procesos de alteración de la composición social, desarticula la mayoría de las propuestas críticas que se formulan desde la acción artística, fagocitándolas con intereses inmobiliarios, empresariales, financieros...

La gentrificación afecta especialmente a la memoria colectiva barrial, imposibilitando la reconstrucción del pasado, provocando la pérdida de la identidad local. Los desplazados son los afectados últimos por el proceso de gentrificación.

\section{Glocalización}

Entendemos que la gentrificación es una respuesta aspiracional de las administraciones públicas locales a una política del desarrollo urbano global, cuya finalidad es la implantación de lo denominado como "ciudades marca". No hay dos procesos de gentrificación iguales en su desarrollo. Proponemos trabajar desde lo local, desde la especificidad que estos procesos alcanzan en cada contexto, para identificar las herramientas que cada comunidad genera para abordar el conflicto global. 


\section{perifèria}

Número 18, junio 2013

http://revistes.uab.cat/periferia

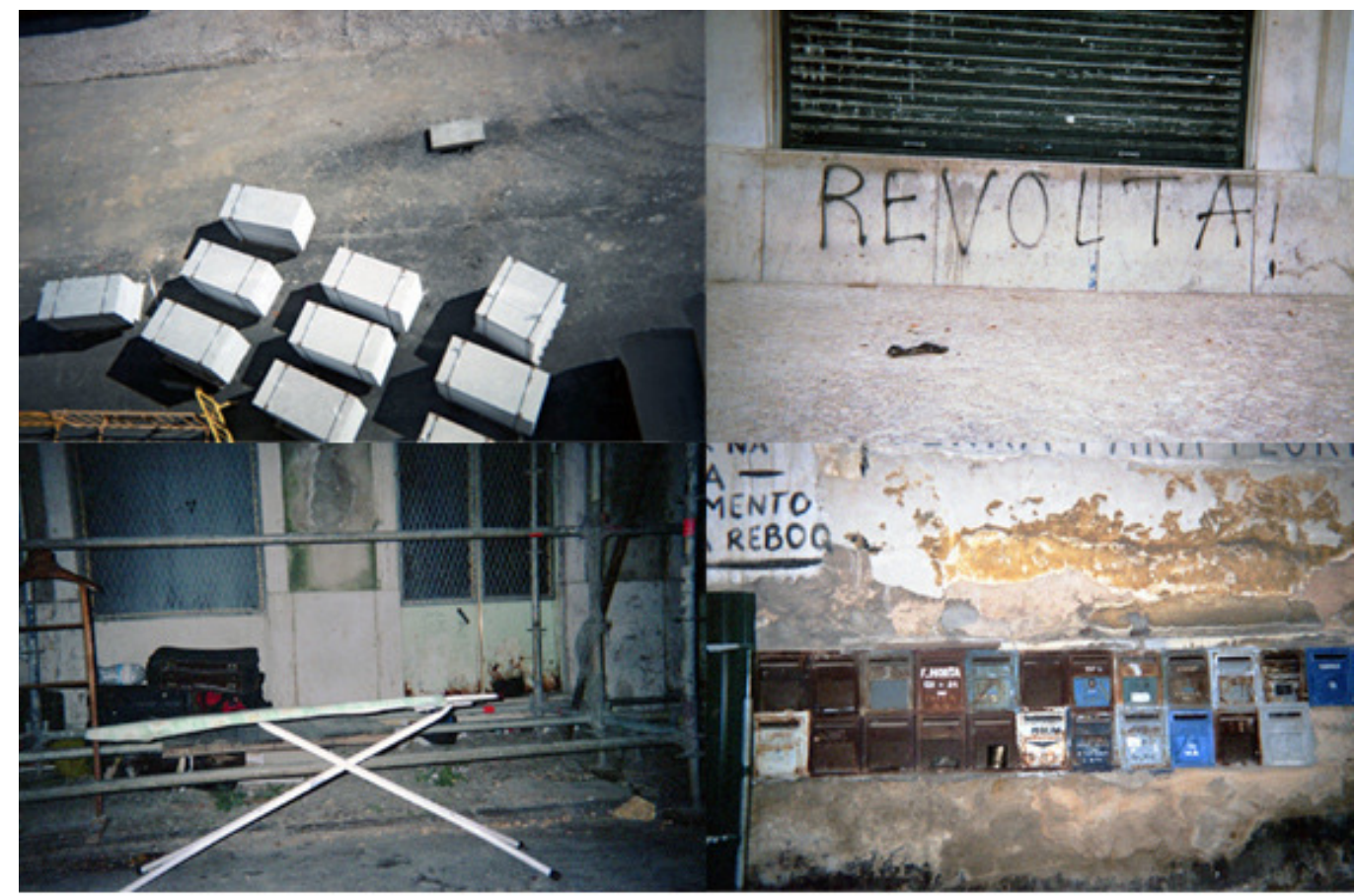

Intendente(s) de Hélène Veiga

Investigación sobre el papel de las imagenes en los procesos de transformación del paisaje urbano a partir de la zona de Intendente (Lisboa)

\section{Archivo de subjetividades}

Museo de los Desplazados nació en diciembre de 2011 y a día de hoy cuenta con cerca de 40 colaboraciones, que registran 23 casos de gentrificación en 10 países del mundo, y sigue creciendo cada día. De igual forma, la plataforma alimenta un archivo de documentación teórica que recoge información general sobre la gentrificación: artículos sobre casos concretos, bibliografía, cine y documental sobre la gentrificación y todo tipo de referencias y links relacionados. www.museodelosdesplazados.com

Identificamos la forma de archivo, previa renuncia a su aspiración de definición totalitaria de los elementos y tipologías desplazadas, como herramienta de

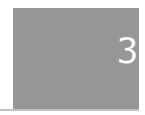




\section{perifèria}

Número 18, junio 2013

http://revistes.uab.cat/periferia

acercamiento y empatización hacia todo aquello que se pierde en procesos que, como el de la gentrificación, suponen la creación de espacios excluyentes y de segregación social.

Frente a la creación de comunidades cerradas, proponemos el Museo de los Desplazados como una plataforma abierta, incompleta, en continuo proceso de desarrollo y necesariamente colectiva. Es en esa colectividad también dónde decidir si es este un archivo de lo que hay que olvidar o recuperar.

\section{Plataforma de colaboración}

El Museo de los Desplazados se crea con la participación de colaboradores locales que con sus registros dan forma a este contenedor. El valor único de la plataforma son las experiencias personales e irregistrables que cada colaborador adquiere en el proceso.

Cada ciudad o área desarrolla sus líneas propias y específicas, y conserva la autonomía de llegar a sus propias conclusiones durante el proceso de registro. Proponemos trabajar desde la interrelación con los perfiles potencialmente en peligro de ser desplazados por procesos de gentrificación, mediante acciones que impliquen documentación de las transformaciones y/o acercamiento de la información a esos perfiles.

\section{Buscamos colaboradores}

Museo de los Desplazados recoge material de registro de todo aquello que se pierde en los procesos de gentrificación. Todos los soportes de la información son bienvenidos: video, foto, sonido, esquemas de información, etc.

\section{Contacta con nosotros en: hand@lefthandrotation.com}

La plataforma da continuidad a los casos recogidos y comparte información relacionada a través del evento en facebook: Museo De Los Desplazados ("Gentrificación no es un nombre de señora"). 


\section{perifèria}

Número 18, junio 2013

http://revistes.uab.cat/periferia

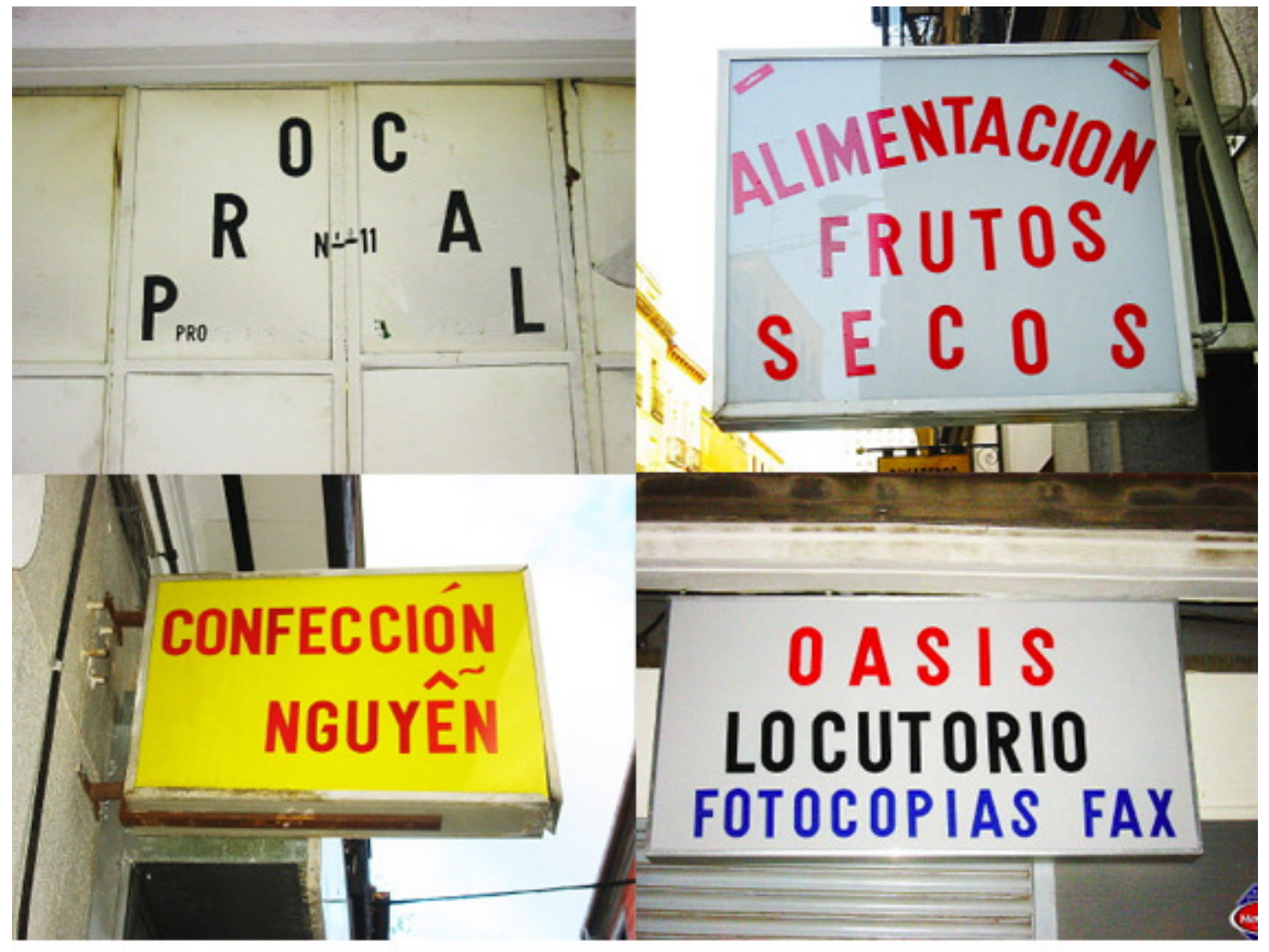

Pifostio de Javier Abarca

Proyecto de preservación de cultura popular. Archivo de ciertos aspectos de la ciudad vivida, improvisada, de clase obrera, que la gentrificación recicla o expulsa. 